\title{
Çeşitli Donlardaki Türk Alaca Atlarının Vücut Ölçülerinin Parametrik Olmayan İstatistik Yöntemler İle İncelenmesi
}

\author{
Şenol ÇELİK ${ }^{* 1}$, Füsun COŞKUN ${ }^{2}$, Orhan YILMAZ ${ }^{3}$ \\ ${ }^{l}$ Bingöl Üniversitesi, Ziraat Fakültesi, Zootekni Bölümü, Bingöl \\ ${ }^{2}$ Ahi Evran Üniversitesi, Ziraat Fakültesi, Zootekni Bölümü, Kırşsehir \\ ${ }^{3}$ Çanakkale Onsekiz Mart Üniversitesi, Ziraat Fakültesi, Zootekni Bölümü, Çanakkale
}

\begin{abstract}
Özet
$\mathrm{Bu}$ çalışmada, Türk Alaca atlarında renk faktörünün çeşitli vücut ölçülerine olan etkisi parametrik olmayan testler ile araştırılmıştır. Parametrik olmayan istatistik yöntemlerden Kruskal-Wallis, Medyan ve JoncheereTerpstra testleri uygulanmıştır. Kruskal-Wallis testi sonuçlarına göre cidago yüksekliği, vücut uzunluğu ve ön incik çevresi değerlerinde istatistik olarak önemli farklllık bulunmuştur $(\mathrm{P}<0.05)$. Medyan testine göre vücut uzunluğu $(\mathrm{P}<0.01)$, göğüs çevresi ve ön incik çevresi değerlerinde istatistik olarak önemli farklllık tespit edilmiştir $(\mathrm{P}<0.05)$. Vücut uzunluğu değerleri Kruskal-Wallis testi sonucunda Doru Alaca ile Alaca Doru, Alaca Yağız, Kırçıl Yağız Alaca, Kula Alaca $(\mathrm{P}<0.05)$ ve Yağız Alaca atları arasında istatistiksel olarak önemli farklılık bulunmuştur $(\mathrm{P}<0.01)$. Ön incik çevresi değerleri Kruskal-Wallis testine göre Doru Alaca atlar ile Alaca Doru, Alaca Yağız, Yağız Alaca atları ve Kula Alaca atlar ile Alaca Doru, Alaca Yağız ve Yağız Alaca atları arasında istatistiki olarak önemli farklılık bulunmuştur $(\mathrm{P}<0.05)$. Cidago yüksekliği değerleri Kruskal-Wallis testine göre Doru Alaca atlarla Alaca Yağız, Kırçıl Yağız Alaca $(\mathrm{P}<0.05)$ ve Yağız Alaca atları arasında istatistiki olarak önemli farklılık tespit edilmiştir $(P<0.01)$. Cidago yüksekliği, göğüs çevresi, vücut uzunluğu ve ön incik çevresi değerleri bakımından Doru Alaca atlarının diğer atlardan daha fazla farklılık oluşturduğu ortaya çıkmıştır.
\end{abstract}

Anahtar Kelimeler: Türk Alaca atı, vücut ölçüsü, Kruskal-Wallis testi, Medyan testi, Joncheere-Terpstra testi

\section{A Study of Body Measurements by Using Nonparametric Statistics Methods in Turkish Spotted Horses in Various Colors}

\begin{abstract}
In this study, the colour factor of Turkish Spotted horses, the effects on various body measurements were investigated by using nonparametric tests. Kruskal-Wallis, median and Joncheer-Terpstra test was applied from non-parametric statistical methods. According to the Kruskal-Wallis test, statistically significant difference was found in the values of wither height, body length and front shank circumference $(\mathrm{P}<0.05)$. According to the median test, statistically significant difference was found in the values of the body length $(\mathrm{P}<0.01)$, chest circumference and front shank circumference $(\mathrm{P}<0.05)$. Body length values were found as statistically significant difference between Doru Alaca with Alaca Doru, Alaca Yağız, Kırçıl Yağız Alaca, Kula Alaca $(P<0.05)$ and Yağız Alaca horses in Kruskal-Wallis test results $(\mathrm{P}<0.01)$. Front shank circumference values were found as statistically significant differences between Doru Alaca with Alaca Doru, Alaca Yağız, Yağız Alaca horses and Kula Alaca with Alaca Doru, Alaca Yağız and Yağız Alaca horses, according to Kruskal-Wallis tests $(\mathrm{P}<0.05)$. Wither height values were found statistically significant differences between Doru Alaca with Alaca Yağız, Kırçıl Yağız Alaca $(\mathrm{P}<0.05)$ and Yağız Alaca horses, according to Kruskal-Wallis test $(\mathrm{P}<0.01)$. It was emerged Doru Alaca horses create more differences than other horses in means of Wither height, chest circumference, body length and front shank circumference values.
\end{abstract}

Keywords: Turkish Spotted horse, body measurement, Kruskal-Wallis test, Median test, Joncheere-Terpstra test

\footnotetext{
*Sorumlu Yazar: senolcelik@bingol.edu.tr
} 


\section{Giriş}

At, Atgiller familyasına dahil tek tırnaklı (toynaklı) memeli bir hayvandır. Çoğu bilim adamı, Türklerin ana vatanı olan Orta Asya steplerinin, evcil atın orijin merkezi olduğu konusunda hemfikirdir [1, 2]. Orta Asya' da atlar binyıllar boyunca, göçebe sürü sahiplerine besin kaynağ sağlamanın yanı sıra savaşta, ulaşımda ve tarımsal faaliyetlerde kullanılmışlardır [3]. 1950'ler ve 1960'larda yerlerini hemen hemen tamamen traktörlerin almasiyla, Avrupa'da, bir dereceye kadar da Türkiye'de atlar, insan yaşamı içindeki önemlerini kaybetmişlerdir [4].

Temel Türk at rrkları, Yerli Anadolu, Ayvacık Midillisi, Camardi Kulası, Canik, Çukurova, Doğu Anadolu, Hinis Kolu Kısası, Karacabey, Malakan, Rahvan, Rumeli (Trakya), Türk Arap ve Uzunyayla olarak sıralanabilirler [5-11].

Türkiye'de 1991 y1lında 495543 olan at sayıs1 2000 y1lında 271000'e, 2012'de 141422'ye ve 2013 y1lında ise 136209'a kadar düşmüştür [12]. Günümüzde Türk çiftçisinin elinde az sayıda at bulunmaktadır. Hafif işlerde, engebeli arazilerde ve bazı bölgelerde şehir içi taşımacılıkta at kullanılmasına devam edilmektedir. Türkiye'de at yarışlarının son zamanlarda gelişmiş olması nedeniyle Arap ve İngiliz atı yetiştiriciliği gelişmiştir. Diğer ülkelerde olduğu gibi Türkiye' de de yarış at1 yetiştiriciliği büyük bir sektör haline gelmiştir. Türkiye'nin farklı bölgelerinde mahalli rahvan koşuları, cirit vb. oyunlar için at yetiştiriciliği yapıldığı bilinmektedir. Az sayıda da olsa sportif amaçlı konkur-hipik atları, süs ve zevk amaçlı minyatür atlar da Türkiye'de beslenmektedir. Son y1llarda silahlı kuvvetler ve emniyet teşkilatlarında, güvenlik amaçlı, atlı birliklerin teşkil edildiği görülmektedir.

Tarih boyunca, atların renkleri ve güzellikleri insanoğlunu etkilemiştir. Özellikle son zamanlarda, atlar, kullanım amaçlarından daha çok estetik özellikleri esas alınarak değerlendirilmektedirler [13-14]. Çoğu insan, diğer tüm vasıfları eşit olduğu halde, kendisini cezbeden renkteki atları duygusal olarak tercih etme eğilimindedir [13-14]. Atlar geniş bir yelpazede vücut rengi ve ayırıcı işaretler sergilerler. Hatta genellikle atlar, değerleri, ırkları ve cinsiyetlerinden ziyade öncelikli olarak vücut renkleri ile tanımlanırlar [8]. Atların renk donları esas donlar, türev donlar ve alaca donlar olmak üzere 3 çeşittir [15]. Alaca donlar, vücutta iki ayrı donda bulunmasıdır.

Türkiye' de atlar üzerine oldukça az çalışma yapılmış olmasına rağmen, az da olsa alaca atlarla ilgili çalışmalar mevcuttur [16]. Atların; cidago yüksekliği, sağrı yüksekliği, vücut uzunluğu, gögüs çevresi, göğüs derinliği, göğüs genişliği, sağrı genişliği, bacak uzunluğu, incik çevresi, baş uzunluğu ve kulak uzunluğu ölçümleri ile ilgili birçok yayın mevcuttur.

$\mathrm{Bu}$ çalışmada değişik donlardaki Türk Alaca atlarının çeşitli vücut ölçülerinin parametrik olmayan istatistik yöntemlerden Kruskal-Wallis, Medyan ve Joncheere-Terpstra Testi ile incelenmesi ve donların vücut ölçüleri üzerindeki etkisinin araştııılması amaçlanmıştır.

\section{Materyal ve Metot}

\subsection{Materyal}

Bu çalışmanın materyalini, Ardahan'ın Göle ilçesinde halk elinde yetiştirilen 30 at oluşturdu. Atların 11'i Doru Alaca, 4'ü Alaca Doru, 4'ü Alaca Yağız, 3'ü Kırçıl Yağız Alaca, 3'ü Kula Alaca ve 5'i ise Yağız Alaca donlardaki atlarıdır. Atlara ait cidago yüksekliği, sağrı yüksekliği, sağrı genişliği, vücut uzunluğu, göğüs genişliğii, göğüs çevresi, göğüs genişliği, ön incik çevresi, baş uzunluğu ve kulak uzunluğu ölçümü yapılmıştır. 


\subsection{Metot}

Araştırma verileri için önce parametrik istatistik testleri uygulanabilmesi için gerekli varsayımların sağlanması gerektiğinden normallik testleri ve varyansların homojenliği testleri yapılmıştır. Normallik testleri için Q-Q grafik yöntemi [17-18], Kolmogorow-Smirnov testi [19] ve Shapiro-Wilk testi [20] testleri uygulanmıştır. Verilerin normal dağılım göstermediği durumlarda parametrik olmayan istatistik yöntemlere başvurulur.

Kruskal-Wallis tarafindan 1952 yılında önerilen Kruskal-Wallis H testi,

$$
H=\frac{12}{N(N+1)} \sum_{i=1}^{C} \frac{R_{i}^{2}}{n_{i}}-3(N+1) \text { şeklinde tanımlanır [21]. }
$$

Burada,

C: örneklem sayısı, $n_{i}$ : n'nci örnekleme ait gözlem sayısı, $N=\sum n_{i}$ : tüm gözlemlerin sayısı, $R_{i}$ : i’nci örneklem için sıra sayıları toplamıdır. Bu test için hipotezler

$H_{0}: \tau_{1}=\tau_{2}=\ldots=\tau_{C}$

$H_{1}: \tau_{i}$ parametrelerinden en az biri diğerlerinden farklıdır şeklinde kurulur [22].

Gruplar arasındaki farklılığın hangileri arasında olduğunu belirlemek için çoklu karşılaştırma testi yapılır [23]. Bağımsız gruplar arasındaki farkın karşılaştırılmasında

$$
\begin{aligned}
& \left|\frac{R_{i}}{n_{i}}-\frac{R_{j}}{n_{j}}\right|>t_{1-(\alpha / 2)} \sqrt{\left(S^{2} \frac{N-1-H}{N-k}\right)\left(\frac{1}{n_{i}}+\frac{1}{n_{j}}\right)} \\
& S^{2}=\frac{1}{n-1}\left(\sum_{\substack{\text { tum rank } \\
\text { değerleri }}}\left(R_{i j}\right)^{2}-\frac{n(n+1)^{2}}{4}\right) \text { formülü kullanılır [24]. }
\end{aligned}
$$

Burada $R_{i}$ ve $R_{j}$ iki gruba ait rankların toplamıdır. Burada $S^{2}$ : varyans, N: gözlem sayısı, k: grup sayısidir.

Medyan test istatistiği,

$$
\sum_{j=1}^{k} \sum_{i=1}^{2} \frac{\left(G_{i j}-B_{i j}\right)^{2}}{B_{i j}} \sim \chi_{(k-1)(2-1)}^{2}
$$

şeklindedir. Burada k: grup sayısı, $G_{i j}$ : gözlenen değerler, $B_{i j}$ : beklenen değerler olup serbestlik derecesi $(\mathrm{k}-1)(2-1)=\mathrm{k}-1$ 'dir [25]. 
Jonckheere-Tespestra testi ise,

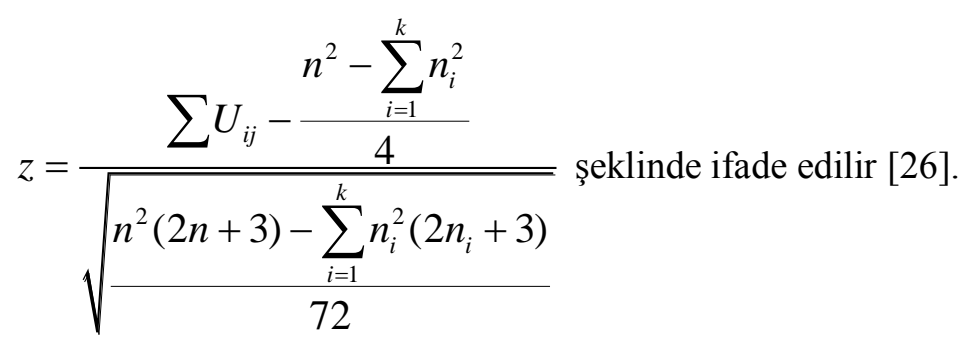

\section{Bulgular ve Tartışma}

Ölçümü yapılan 30 adet Alaca ata ait tanıtıcı istatistikler Tablo 1'de verilmiştir. Buna göre ortalama olarak cidago yüksekliği $135.57 \mathrm{~cm}$, sağrı yüksekliği $136.30 \mathrm{~cm}$, sağrı genişliği $46.30 \mathrm{~cm}$, vücut uzunluğu $138.80 \mathrm{~cm}$, göğüs çevresi $152.77 \mathrm{~cm}$, göğüs derinliği $61.50 \mathrm{~cm}$, göğüs genişliği $39.10 \mathrm{~cm}$, ön incik çevresi $17.72 \mathrm{~cm}$, baş uzunluğu $52.27 \mathrm{~cm}$ ve kulak uzunluğu 13.43 olarak saptanmıştır.

Tablo 1. Atların vücut ölçülerine ilişkin tanıtıcı istatistikler

\begin{tabular}{lcrrrrr}
\hline Değişkenler & $\mathbf{N}$ & En küçük & En büyük & \multicolumn{1}{c}{$\bar{X}$} & \multicolumn{1}{c}{$s_{\bar{x}}$} & \multicolumn{1}{c}{$\mathbf{s}$} \\
\hline Cidago yüksekliği & 30 & 115.00 & 144.00 & 135.57 & 1.37 & 7.51 \\
Sağrı yüksekliği & 30 & 119.00 & 145.00 & 136.30 & 1.09 & 5.97 \\
Sağrı genişliği & 30 & 36.00 & 52.00 & 46.30 & 0.74 & 4.05 \\
Vücut uzunluğu & 30 & 105.00 & 154.00 & 138.80 & 2.29 & 12.54 \\
Göğüs çevresi & 30 & 115.00 & 169.00 & 152.77 & 2.16 & 11.83 \\
Göğüs derinliği & 30 & 46.00 & 69.00 & 61.50 & 1.01 & 5.53 \\
Göğüs genişliği & 30 & 28.00 & 45.00 & 39.10 & 0.61 & 3.36 \\
Ön incik çevresi & 30 & 14.00 & 20.00 & 17.72 & 0.27 & 1.51 \\
Baş uzunluğu & 30 & 44.00 & 60.00 & 55.27 & 0.67 & 3.67 \\
Kulak uzunluğu & 30 & 10.50 & 15.50 & 13.43 & 0.23 & 1.26 \\
\hline
\end{tabular}

$\bar{X}$ : Ortalama, $s_{\bar{x}}:$ Standart hata, s: Standart sapma

Tablo 2. Kolmogorov-Simirnov ve Shapiro-Wilk normallik testi

\begin{tabular}{lcccccc}
\hline Değişkenler & Kolmogorov-Smirnov & sd & $\mathbf{p}$ & Shapiro-Wilk & sd & p \\
\hline Cidago yüksekliği & 0.19 & 30 & 0.006 & 0.83 & 30 & 0.000 \\
Sağr1 yüksekliği & 0.18 & 30 & 0.011 & 0.83 & 30 & 0.000 \\
Sağr1 genişliği & 0.20 & 30 & 0.003 & 0.84 & 30 & 0.000 \\
Vücut uzunluğu & 0.14 & 30 & 0.162 & 0.86 & 30 & 0.001 \\
Göğüs çevresi & 0.21 & 30 & 0.002 & 0.86 & 30 & 0.001 \\
Göğüs derinliği & 0.19 & 30 & 0.006 & 0.87 & 30 & 0.002 \\
Göğüs genişliği & 0.15 & 30 & 0.094 & 0.91 & 30 & 0.018 \\
Ön incik çevresi & 0.17 & 30 & 0.021 & 0.93 & 30 & 0.037 \\
Baş uzunluğu & 0.15 & 30 & 0.090 & 0.92 & 30 & 0.028 \\
Kulak uzunluğu & 0.24 & 30 & 0.000 & 0.93 & 30 & 0.038 \\
\hline
\end{tabular}

Tablo 2'de Kolmogorov-Simirnov normallik testine göre gögüs genişliği ve baş uzunluğu değerleri normal dağılım gösterirken $(\mathrm{p}>0.05)$, diğer değişkenlerin verileri normal dağılım göstermemiştir ve istatistiki olarak önemli bulundu $(\mathrm{p}<0.05)$. Shapiro-Wilk normallik testine göre bütün değişenlere ait verilerin normal dağılıma uygun olmadığı tespit edildi $(p<0.05)$. Genel olarak bütün değişken verilerinde normallik şartı sağlanmadığ 1 için parametrik olmayan testlerin kullanılmasının gerekli olduğu görüldü. 
Atların vücut ölçülerinin çeşitli donlara göre karşılaştırılmaları parametrik olmayan testlerden Kruskal-Wallis, Medyan ve Joncheere-Terpstra Testi ile yapıldı ve elde edilen bulgular Tablo 3, Tablo 4 ve Tablo 5'de gösterildi. Tablo 3'te verilen Kruskal-Wallis testine göre atlarda sağrı yüksekliği, sağr1 genişliği, göğüs çevresi, göğüs derinliği, göğüs genişliği, baş uzunluğu ve kulak uzunluğu değerleri renklere göre istatistiksel olarak önemli olmadığ 1 görüldü. Ancak cidago yüksekliği, vücut uzunluğu ve ön incik çevresi değerleri atların renklerine göre istatistiksel olarak önemli farklılıklar bulundu $(\mathrm{P}<0.05)$. Tablo 4'te verilen Medyan testine göre atlarda cidago yüksekliği, sağrı yüksekliği, sağr1 genişliği, göğüs derinliği, göğüs genişliği, baş uzunluğu ve kulak uzunluğu değerleri renklere göre istatistiksel olarak önemli bir farklılık tespit edilemedi. Ancak vücut uzunluğu $(\mathrm{P}<0.01)$, göğüs çevresi ve ön incik çevresi değerleri $(\mathrm{P}<0.05)$ atların renklerine göre istatistiksel olarak önemli farklılık gösterdiği, Tablo 5'de verilen Joncheere-Terpstra testine göre atların vücut ölçülerinde donlara göre istatistiksel olarak önemli farklılık olmadığı görüldü $(\mathrm{P}>0.05)$. Farklılık bulunan ölçüm değerlerinin hangilerinin hangi renklere göre farklılık gösterdiği çoklu karşılaştırma testi ile belirlendi. Kruskal-Wallis testinden elde edilen bulgulara göre Tablo 6' da cidogo yüksekliği değerleri; Doru Alaca-Alaca Yağız, Doru Alaca-Kırçıl Yağız Alaca ve Doru Alaca-Yağız Alaca atları arasında, Tablo 7'de vücut uzunluğu değerleri; Doru Alaca-Alaca Doru, Doru Alaca-Alaca Yağız, Doru Alaca-Kırçı1 Yağız Alaca, Doru Alaca-Kula Alaca ve Doru Alaca-Yağız Alaca atları arasında istatistiki olarak önemli farkl11ıklar olduğu görüldü $(\mathrm{P}<0.05)$. Tablo 8'de ön incik çevresi değerleri; Doru Alaca-Alaca Doru, Doru Alaca-Alaca Yağız, Doru Alaca-Yağız Alaca, Kula Alaca-Alaca Doru, Kula Alaca-Alaca Yağız ve Kula Alaca-Yağız Alaca atları arasında istatistiki olarak önemli farklılıklar tespit edildi $(\mathrm{P}<0.05)$. Bu sonuçlardan görüldüğü gibi bütün test sonuçları incelendiğinde; sağrı yüksekliği, sağr1 genişliği, göğüs derinliği, göğüs genişliği, baş uzunluğu ve kulak uzunluğu ölçülerinde donlara göre farklılık önemsiz bulundu ( $\mathrm{P}>0.05)$. Doru Alaca-Alaca Yağız ve Doru Alaca-Yağız Alaca atları arasındaki farklılık cidago yüksekliği, vücut uzunluğu ve ön incik çevresi ölçülerinde önemli iken, Doru Alaca ile diğer tüm dondaki atların vücut uzunluğu arasındaki farklılık önemli bulundu. Vücut uzunluğuna Doru Alaca atlarının diğer atlardan daha fazla etki yaptı̆̆ görüldü. Cidago yüksekliği, vücut uzunluğu ve ön incik çevresi ölçülerinde en çok farklılık Doru Alaca atlarından kaynaklanmaktadır.

Tablo 3. Vücut ölçülerine ait Kruskal-Wallis testi sonuçları

\begin{tabular}{lrrrrrrrrrr}
\hline $\begin{array}{c}\text { Cidago } \\
\text { yük. }\end{array}$ & \multicolumn{1}{c}{$\begin{array}{c}\text { Sağrı } \\
\text { yük. }\end{array}$} & $\begin{array}{c}\text { Sağrı Vücu } \\
\text { gen. }\end{array}$ & $\begin{array}{l}\text { Gü uz. } \\
\text { cŏğüs } \\
\text { cev. }\end{array}$ & $\begin{array}{c}\text { Göğüs } \\
\text { der. }\end{array}$ & $\begin{array}{c}\text { Göğüs } \\
\text { gen. }\end{array}$ & $\begin{array}{c}\text { Ön incik } \\
\text { çev. }\end{array}$ & $\begin{array}{c}\text { Baş } \\
\text { uz. }\end{array}$ & $\begin{array}{c}\text { Kulak } \\
\text { uz. }\end{array}$ \\
\hline$\chi^{2}$ & 11.17 & 8.03 & 7.65 & 14.50 & 9.45 & 9.21 & 2.73 & 13.73 & 7.92 & 2.25 \\
Sd & 5 & 5 & 5 & 5 & 5 & 5 & 5 & 5 & 5 & 5 \\
p & 0.048 & 0.154 & 0.176 & 0.013 & 0.093 & 0.101 & 0.742 & 0.017 & 0.161 & 0.813 \\
\hline
\end{tabular}

Tablo 4. Vücut ölçülerine ait Medyan testi sonuçları

\begin{tabular}{|c|c|c|c|c|c|c|c|c|c|c|}
\hline & $\begin{array}{c}\text { Cidago } \\
\text { yük. }\end{array}$ & $\begin{array}{l}\text { Sağrı } \\
\text { yük. }\end{array}$ & $\begin{array}{l}\text { Sağrı } \\
\text { gen. }\end{array}$ & $\begin{array}{l}\text { Vücut } \\
\text { uz. }\end{array}$ & $\begin{array}{c}\text { Göğğüs } \\
\text { çev. }\end{array}$ & $\begin{array}{c}\text { Göğüss } \\
\text { der. }\end{array}$ & $\begin{array}{l}\text { Göğüs } \\
\text { gen. }\end{array}$ & $\begin{array}{c}\text { Ön } \\
\text { incik } \\
\text { çev. }\end{array}$ & $\begin{array}{l}\text { Baş } \\
\text { uz. }\end{array}$ & $\begin{array}{c}\text { Kulak } \\
\text { uz. }\end{array}$ \\
\hline $\mathbf{N}$ & 30 & 30 & 30 & 30 & 30 & 30 & 30 & 30 & 30 & 30 \\
\hline Medyan & 138.00 & 138.00 & 47.00 & 141.50 & 155.50 & 62.00 & 39.50 & 18.00 & 55.00 & 14.00 \\
\hline$X^{2}$ & 8.55 & 6.53 & 8.85 & 18.67 & 11.92 & 8.31 & 3.29 & 14.50 & 8.04 & 2.82 \\
\hline sd & 5 & 5 & 5 & 5 & 5 & 5 & 5 & 5 & 5 & 5 \\
\hline $\mathbf{p}$ & 0.129 & 0.258 & 0.115 & 0.002 & 0.036 & 0.140 & 0.656 & 0.013 & 0.154 & 0.727 \\
\hline
\end{tabular}


Tablo 5. Vücut ölçülerine ait Joncheere-Terpstra testi sonuçları

\begin{tabular}{|c|c|c|c|c|c|c|c|c|c|c|}
\hline & Cidago yük. & $\begin{array}{l}\text { Sağrı } \\
\text { yük. }\end{array}$ & $\begin{array}{l}\text { Sağrı } \\
\text { Gen. }\end{array}$ & Vücut uz. & $\begin{array}{l}\text { Göğüs } \\
\text { Çev. }\end{array}$ & $\begin{array}{l}\text { Göğ̈üs } \\
\text { Der. }\end{array}$ & $\begin{array}{c}\text { Göğg̈us } \\
\text { Gen. }\end{array}$ & $\begin{array}{c}\text { Ön } \\
\text { incik } \\
\text { çev. }\end{array}$ & Baş uz. & $\begin{array}{c}\text { Kulak } \\
\text { uz. }\end{array}$ \\
\hline $\mathrm{N}$ & 30 & 30 & 30 & 30 & 30 & 30 & 30 & 30 & 30 & 30 \\
\hline $\begin{array}{l}\text { Gözlemlenen J-T } \\
\text { istatistiği }\end{array}$ & 146.50 & 154.00 & 163.50 & 147.00 & 187.50 & 153.00 & 171.50 & 183.50 & 180.00 & 170.00 \\
\hline $\begin{array}{l}\text { Ortalama J-T } \\
\text { istatistiği }\end{array}$ & 176.00 & 176.00 & 176.00 & 176.00 & 176.00 & 176.00 & 176.00 & 176.00 & 176.00 & 176.00 \\
\hline $\begin{array}{l}\text { J-T istatistiğin } \\
\text { standart sapmas1 }\end{array}$ & 26.966 & 26.961 & 26.860 & 27.036 & 27.026 & 26.941 & 26.861 & 26.682 & 26.871 & 26.30 \\
\hline $\begin{array}{l}\text { Standart. J-T } \\
\text { istatistiği }\end{array}$ & -1.094 & -0.816 & -0.465 & -1.073 & 0.426 & -0.854 & -.0168 & 0.281 & 0.149 & -0.23 \\
\hline $\mathrm{p}$ & 0.274 & 0.415 & 0.642 & 0.283 & 0.670 & 0.393 & 0.867 & 0.779 & 0.882 & 0.820 \\
\hline
\end{tabular}

Tablo 6. Cidago yüksekliği için çoklu karşılaştırmalar (Kruskal-Wallis test sonucu)

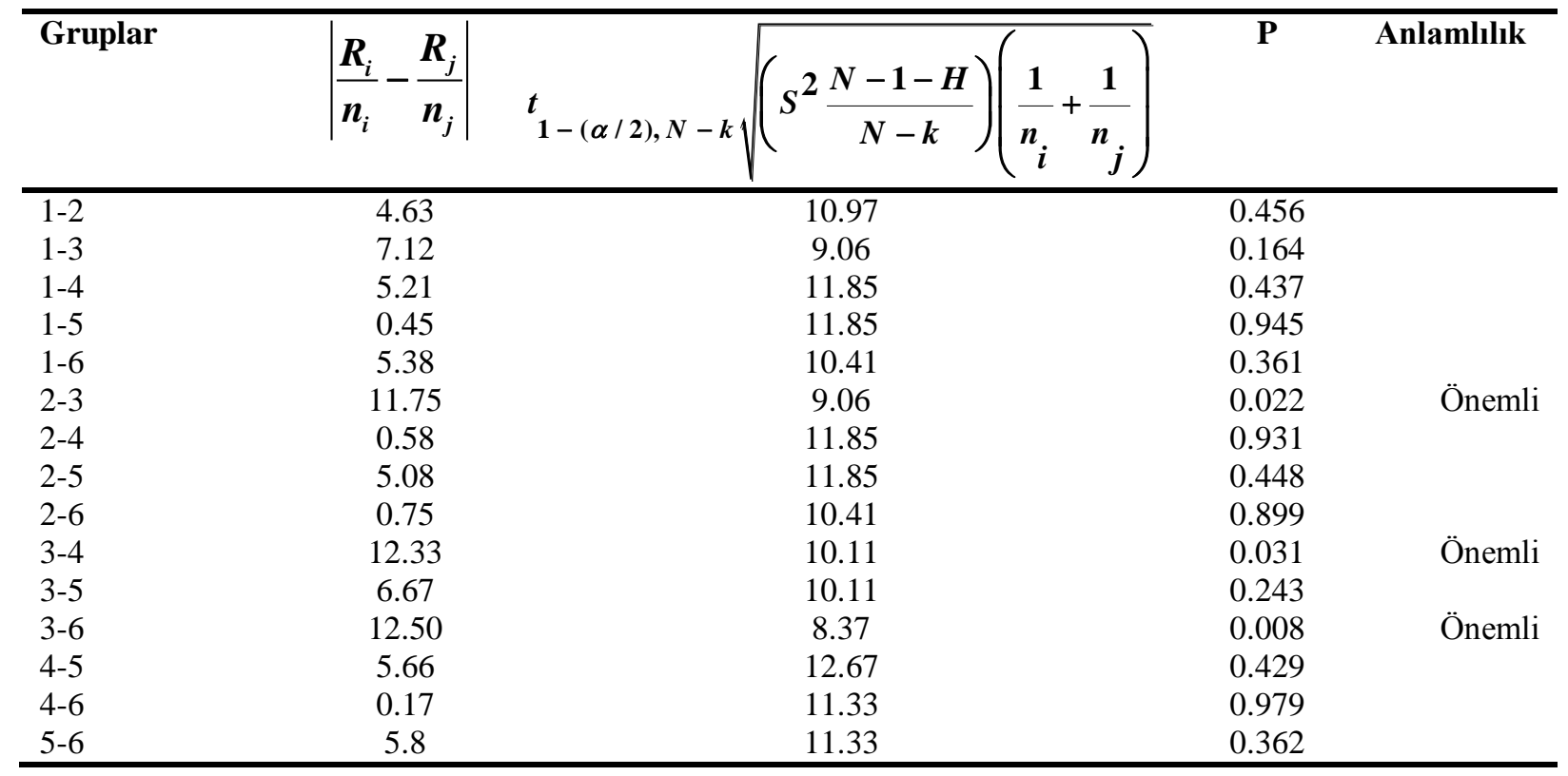

$t_{1-(\alpha / 2), N-k}=2.045$. 1: Alaca Doru, 2: Alaca Yağız, 3: Doru Alaca, 4: Kırçıl Yağız Alaca,

5: Kula Alaca, 6: Yağız Alaca. 
Tablo 7. Vücut uzunluğu için çoklu karşılaştırmalar (Kruskal-Wallis test sonucu)

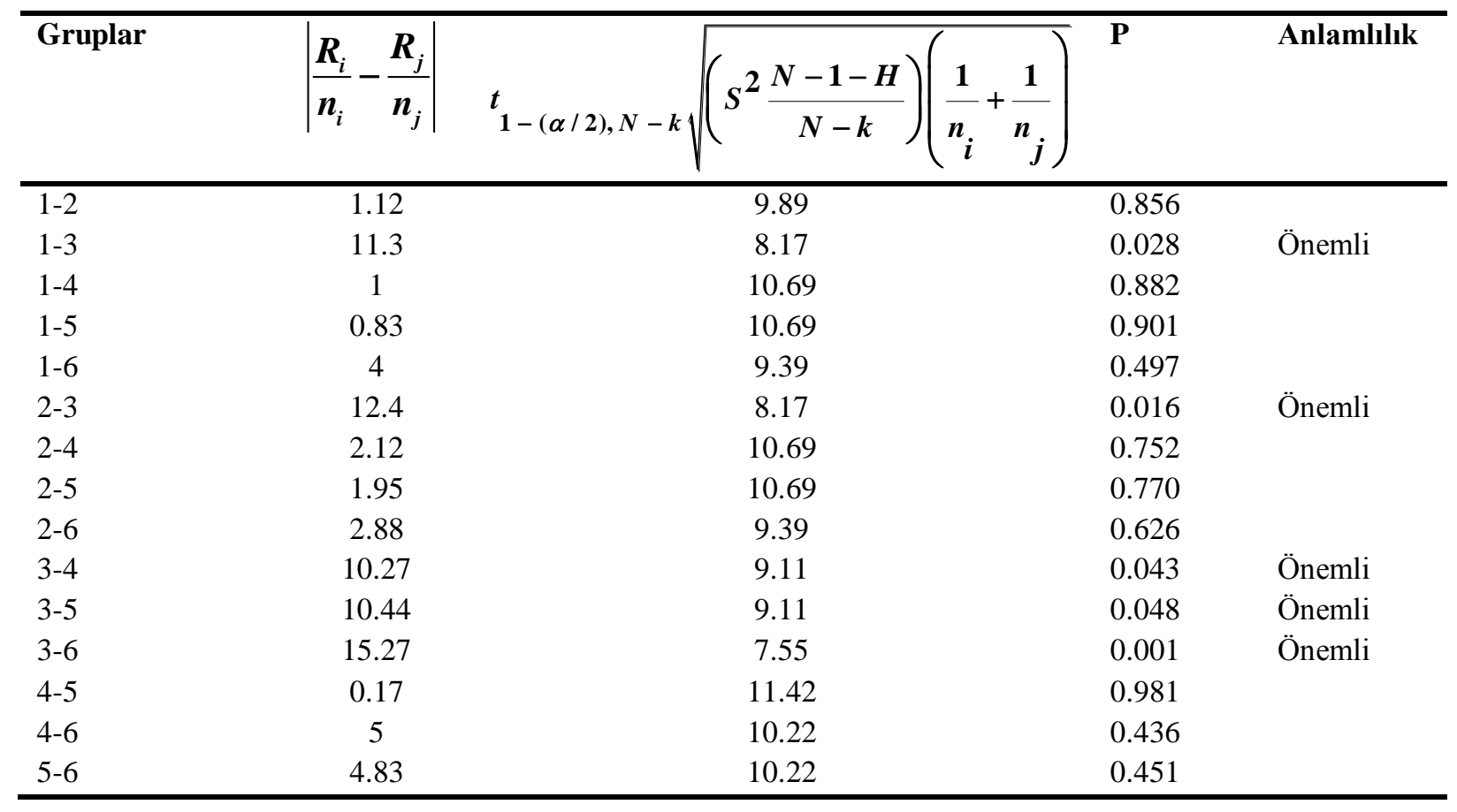

$t_{1-(\alpha / 2), N-k}=2.045$. 1: Alaca Doru, 2: Alaca Yağız, 3: Doru Alaca, 4: Kırçıl Yağız Alaca,

5: Kula Alaca, 6: Yağız Alaca.

Tablo 8. Ön incik çevresi için çoklu karşılaştırmalar (Kruskal-Wallis test sonucu)

\begin{tabular}{|c|c|c|c|c|}
\hline Gruplar & $\frac{\boldsymbol{R}_{i}}{\boldsymbol{n}_{i}}-\frac{\boldsymbol{R}_{j}}{n_{j}}$ & 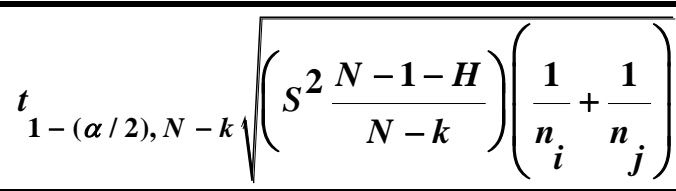 & $\overline{\mathbf{P}}$ & Anlamlılık \\
\hline $1-2$ & 1.13 & 10.22 & 0.855 & \\
\hline $1-3$ & 12.14 & 8.38 & 0.017 & Önemli \\
\hline $1-4$ & 4.50 & 10.97 & 0.497 & \\
\hline $1-5$ & 14.33 & 10.97 & 0.031 & Önemli \\
\hline $1-6$ & 0.10 & 9.63 & 0.986 & \\
\hline $2-3$ & 11.01 & 10.22 & 0.030 & Önemli \\
\hline $2-4$ & 3.37 & 8.38 & 0.611 & \\
\hline $2-5$ & 13.20 & 10.97 & 0.046 & Önemli \\
\hline $2-6$ & 1.03 & 9.63 & 0.860 & \\
\hline $3-4$ & 7.64 & 9.35 & 0.177 & \\
\hline $3-5$ & 2.19 & 9.35 & 0.698 & \\
\hline $3-6$ & 12.04 & 7.74 & 0.010 & Önemli \\
\hline $4-5$ & 9.83 & 11.72 & 0.165 & \\
\hline $4-6$ & 4.40 & 10.49 & 0.488 & \\
\hline $5-6$ & 14.23 & 10.49 & 0.025 & Önemli \\
\hline
\end{tabular}

$t_{1-(\alpha / 2), N-k}=2.045$. 1: Alaca Doru, 2: Alaca Yağız, 3: Doru Alaca, 4: Kırçıl Yağız Alaca,

5: Kula Alaca, 6: Yağız Alaca. 


\section{Sonuçlar}

Yapılan bu çalışmada Alaca Doru, Alaca Yağız, Doru alaca, Kırçıl Yağız Alaca, Kula Alaca ve Yağız Alaca atlarında Kruskal-Wallis testi sonuçlarına göre cidago yüksekliği, vücut uzunluğu ve ön incik çevresi değerlerinde $(\mathrm{P}<0.05)$, Medyan testine göre göğ̈̈s çevresi, ön incik çevresi $(\mathrm{P}<0.05)$ ve vücut uzunluğu değerlerinde istatistik olarak önemli farkl11ıklar bulundu $(\mathrm{P}<0.01)$. Vücut uzunluğu değerleri; Kruskal-Wallis testi sonucu, çoklu karşılaştırmalarda Doru Alaca-Alaca Doru, Doru Alaca-Alaca Yağız, Doru Alaca-Kırçıl Yağız Alaca, Doru Alaca-Kula Alaca $(\mathrm{P}<0.05)$ ve Doru Alaca-Yağız Alaca atları arasında istatistiki olarak önemli farklılıklar tespit edildi $(\mathrm{P}<0.01)$. Ön incik çevresi değerleri de çoklu karşılaştırmalarda Doru Alaca-Alaca Doru, Doru Alaca-Alaca Yağız, Doru Alaca-Yağız Alaca, Kula Alaca-Alaca Doru, Kula Alaca-Alaca Yağız ve Kula Alaca-Yağız Alaca atları arasında istatistiki olarak önemli farkl11ıklar tespit edildi $(\mathrm{P}<0.05)$. Kruskal-Wallis testine göre cidago yüksekliği değerleri; Doru Alaca-Alaca Yağız, Doru Alaca-Kırçıl Yağız Alaca ve Doru Alaca-Yağız Alaca atları arasında istatistiki olarak önemli farklılıklar gözlendi $(\mathrm{P}<0.05)$. Doru Alaca atlarının cidago yüksekliği, göğüs çevresi, vücut uzunluğu ve ön incik çevresi değerlerinde daha çok farklılık oluşturduğu sonucuna ulaşıldı. Vücut uzunluğu ölçülerinde farklılığın en büyük nedeninin Doru Alaca atlar olduğu görüldü. Vücut uzunluğu ölçüleri başta olmak üzere diğer ölçüler için oluşturulacak kriterler üzerinde Doru Alaca atları tercih edilebilir. Donların vücut ölçüleri üzerinde etkili olduğu ortaya çıktı.

\section{Kaynaklar}

1. Düzgüneş O. 1946. Atçılık (Üretme, Bakım ve Yemleme Usulleri), Ali Rıza İncealemdaroğlu Matbaas1, Zonguldak.

2. Yarkın İ. 1962. Atçılık, A. Ü. Ziraat Fakültesi Yayınları: 40, Ders Kitabı: 20, A.Ü. Basımevi, Ankara, 80-94.

3. Wilson R.T. 1999. Horses in Kyrgyz Republic, Draught Animal News, University of Edinburgh, UK., 30: 2-6.

4. Herold P., Hess J. 2001. Draught Animal Power in Organic Farming in Germany, A comparison of horse-drawn and tractor-drawn mowers, Draught Animal News, University of Edinburgh, UK., 35: 21-23.

5. Batu S. 1962. Türk Atları ve At Yetiştirme Bilgisi, A.Ü. Veteriner Fakültesi Yayınları: 13, 93s. Ankara.

6. Sönmez R. 1973. At Yetiştirme (Özel Zootekni). E.Ü. Ziraat Fakültesi Yayınları: 141. E.Ü. Basımevi, İzmir.

7. Arpacik R. 1996. At Yetiştiriciliği. Şahin Matbaası, 6s, Ankara.

8. Emiroğlu K., Yüksel A. 2010. Yoldaşımız At, Yapı Kredi Yayınları, İstanbul, 29-33.

9. Güleç E. 2005. Türk At Irkları, Anadolu At Irklarını Yaşatma ve Geliştirme Derneği Yayınları (Elde basim, ISBN: 975-95931-0-6), Ankara.

10. Kırmızıbayrak T., Aksoy A.R, Tilki M., Saatçi M. 2004. Kars Yöresi Türk Yerli Atlarının Morfolojik Özelliklerinin İncelenmesi, Kafkas Üniversitesi Vet. Fak. Dergisi, 17: 69-72.

11. Bayram D., Öztürk Y., Küçük M. 2005. Van Yöresinde Yetiştirilen Atlarda Fenotipik Özellikler, Yüzüncü Y1l Üniversitesi Veteriner Fakültesi Dergisi, 16 (1): 85-88.

12. TÜİK, 2013. Hayvancılık istatistikleri. http://tuikapp.tuik.gov.tr/hayvancilikapp. (Erişim tarihi: 27.08.2014)

13. Anonim, 2011. Coat Colour. www.apha.com/breed/index. (Erişim tarihi: 26.02.2011).

14. Anonim, 2011. Coat Colour of Horse. www.horsecolor.com. (Erişim tarihi: 26.02.2011). 
15. Özbeyaz Ö., Akçapınar H. 2006. At Yetiştiriciliği Ders Notları, Ankara Üniversitesi Veteriner Fakültesi, 90s, Ankara.

16. Yılmaz O., Ertuğrul M. 2011. Description of Coloured Horses Raised in Turkey, Journal of Agricultural Science and Technology, 3 (3): 203-206.

17. Johnson R.A., Wichern D.W. 1992. Applied Multivariate Statistical Analysis. New Jersey, Prentice-Hall Inc., 166-171.

18. Alpar R. 2011. Uygulamalı Çok Değişkenli İstatistiksel Yöntemler, Detay Yayıncılık, 853s. Ankara.

19. Lehmann E.L. 1986. Testing Statistical Hypotheses, Wiley series in probability and mathematical statistics, 600p., New York.

20. Pearson A.V., Hartley H.O. 1972. Biometrika Tables for Statisticans, Vol 2. Cambiridge, 403p., England.

21. Kruskal W.H., Wallis W.A. 1952. Use of Rank in one-criterion analysis of variance, Journal of the American Statistical Associations, 47 (260): 583-621.

22. Hollander M., Wolfe D.A. 1973. Nonparametric Statsitics Methods. John Wiley and Sons, 503p., New York.

23. Doğan İ., Doğan N. 2014. Çoklu Karşılaştırma Yöntemleri. Detay Yayıncılık, Ankara, 199s.

24. Conover W.J. 1980. Practical Nonparametric Statistics, John Wiley and Sons, Inc., 493p. New York.

25. Gamgam H., Altunkaynak B. 2008. Parametrik Olmayan İstatistik SPSS Uygulamaları, Gazi Kitabevi, Ankara, 313-315.

26. Doğan İ., Doğan N. 2014. Adım Adım Çözümlü Parametrik Olmayan İstatistiksel Yöntemler, Detay Yayıncıllk, Ankara, 93-95. 